arthritis (PsA). There is plenty of evidence that early diagnosis of PsA remains suboptimal leading to poorer outcomes.

Objectives: The objective of this proof-of-concept study was to utilise community pharmacists in collaboration with the local Rheumatology service to screen patients with psoriasis aiming to achieve earlier diagnosis of PsA.

Methods: A pilot site was identified including a community pharmacy with a neighbouring GP surgery. An educational session was organised with the team to help them understand the need for the project. Logistics were finalised and a dedicated teaching was delivered covering PsA and Psoriasis Epidemiology Screening Tool (PEST) tool. PEST was chosen for its high sensitivity and specificity and positive NICE recommendation.

The dispensing personnel highlighted all patients requesting prescribed standard psoriasis-treating topical applications to the pharmacists. They confirmed the history of psoriasis with the patients, ensured the absence of a formal diagnosis of arthritis and offered the PEST questionnaire. Those who scored positive were signposted to their GPs for further consultation. The data was gathered anonymously and analysed to assess the utility of the service.

Results: 37 patients were identified during the 12-week proof of concept phase. $24(65 \%)$ participants were women. Median age of the group was 48 years (range 19-73). 23/37 (62\%) were white Caucasians with eight Asian and three each of Afro-Caribbean or Mixed race background. 18/37 (48\%) answered yes to three or more of five-question PEST tool thereby scoring positive. Ten (27\%) replies were negative and another nine (24\%) declined to pariticipate. No reasons were offered for not filling in the questionnaire. Two of the positive patients have since been reviewed by GP and referred to Rheumatology for further evaluation.

Conclusions: To our knowledge, this is the first study ever conducted utilising community pharmacists to employ a screening questionnaire to help early identification of possible PsA patients. This novel approach of involving community pharmacy helps explore new and proactive ways of early detection of psoriasis patients at risk of PsA and challenges the traditional model of confining the screening process to GPs in primary care. Early findings have already identified nearly half of this cohort with hitherto potentially undiagnosed PsA. This pioneering development highlights a new model of care streamlining the diagnostic pathway thereby providing better quality of care. Considering over $90 \%$ of psoriasis is managed in primary care, it would also encourage quicker assessment by a rheumatologist without burdening the already busy GP practices. Focused strategy and better utilisation of community pharmacists can be pivotal to providing better care for PsA patients in the long term.

Disclosure of Interest: None declared

DOI: 10.1136/annrheumdis-2018-eular.1305

\section{FRI0631 WORKFORCE REQUIREMENTS IN RHEUMATOLOGY: A SYSTEMATIC LITERATURE REVIEW INFORMING THE DEVELOPMENT OF A WORKFORCE PREDICTION QUALITY APPRAISAL TOOL}

P. Putrik ${ }^{1}$, J. Unger ${ }^{2}$, F. Buttgereit ${ }^{3}$, D. Aletaha ${ }^{4}$, G. Bianchi ${ }^{5}$, J. W. Bijlsma ${ }^{6}$, A. Boonen $n^{1}$, N. Cikes ${ }^{7}$, J. Madruga Dias ${ }^{8}$, L. Falzon ${ }^{9}$, A. Finckh ${ }^{10}$, L. Gossec ${ }^{11}$, T. K. Kvien ${ }^{12}$, E. Matteson ${ }^{13}$, F. Sivera ${ }^{14}$, T. Stamm ${ }^{4}$, Z. Szekanecz ${ }^{15}$, D. Wiek ${ }^{16}$ A. Zink ${ }^{17}$, C. Dejaco ${ }^{18}$, S. Ramiro ${ }^{19} .{ }^{1} M U M C$, Maastricht, Netherlands, ${ }^{2} F H$ JOANNEUM, University of Applied Sciences, Bad Gleichenberg, Graz, Austria, ${ }^{3}$ Charitè University Berlin, Berlin, Germany, ${ }^{4}$ Medical University Vienna, Vienna, Austria, ${ }^{5}$ Locomotor System, ASL3-Azienda Sanitaria Genovese, Genova, Italy, ${ }^{6}$ UMC Utrecht, Utrecht, Netherlands, ${ }^{7}$ University of Zagreb School of Medicine, Zagreb, Croatia, ${ }^{8}$ Centro Hospitalar Médio Tejo, Lisbon, Portugal, ${ }^{9}$ Columbia UMC, New York, United States, ${ }^{10}$ University Hospital of Geneva, Geneva, Switzerland, ${ }^{11}$ Sorbonne Universités, UPMC University Paris, Paris, France, ${ }^{12}$ Diakhjemmet Hospital, Oslo, Norway, ${ }^{13}$ Mayo Clinic College of Medicine, Rochester, United States, ${ }^{14}$ Hospital General Universitario de Elda, Elda, Spain, ${ }^{15}$ University of Debrecen, Debrecen, Hungary, ${ }^{16}$ EULAR Standing Committee of PARE, Zurich, Switzerland, ${ }^{17}$ Deutsches Rheuma-Forschungszentrum, Berlin, Germany, ${ }^{18}$ Medical University Graz, Hospital of Bruneck, Graz, Austria, ${ }^{19}$ LUMC, Leiden, Netherlands

Background: Workforce requirement studies should be conducted in order to ensure the right number of people with the right skills, in the right place at the right time to deliver organizational objectives.

Objectives: As part of the EULAR project to develop points to consider for the conduction of workforce studies in rheumatology, we reviewed the literature on workforce prediction with the aim to develop a workforce prediction quality appraisal tool and apply it to existing studies in rheumatology.

Methods: Two literature searches were performed in Ovid MEDLINE, EMBASE, CINAHL, Cochrane Library and the grey literature comprising: (1) an update of a previous systematic literature review (SLR) of workforce prediction studies in rheumatology[1] and (2) a hierarchical SLR of workforce prediction studies in other medical fields. We extracted data on type of model used, details on need, demand and supply factors considered in the model, and other relevant aspects such as regional heterogeneity or uncertainty analyses. Based on the results, key general as well as specific need/demand, and supply factors for workforce calculation in rheumatology were identified and each factor was assigned a quality level (low, moderate, high). The quality appraisal tool was applied to the existing work force modeling studies in rheumatology.

Results: Data was extracted from 14 original workforce prediction studies in rheumatology and 10 SLRs in other fields. Studies used a variety of prediction models based on a heterogeneous set of need and/or demand and/or supply factors. While only a few studies attempted to empirically validate the prediction quality of the model $(n=3)$, the consensus was that an integrated model including all these factors is expected to have the highest validity. Based on the different factors considered in existing studies, our quality appraisal tool included the three groups of factors: general factors (e.g. type of the model, stakeholder involvement), need/demand factors (e.g. scope of diseases covered by rheumatologists, morbidity, demography) and supply factors (e.g. time dedicated to clinical work entry to profession, demographic composition of workforce) (table 1). The majority of studies scored low or moderate on most of the factors.

Table 1 Workforce prediction quality appraisal tool

\begin{tabular}{|c|c|c|}
\hline Factor $^{*}$ & Evidence grading & $\begin{array}{l}\mathrm{N} \text { of } \\
\text { studies }\end{array}$ \\
\hline \multicolumn{3}{|l|}{ General factors } \\
\hline Type of model & $\begin{array}{l}\text { Low: model that was only based on demand or need or supply factors } \\
\text { Moderate: integrated model that considered demand, need and supply } \\
\text { [supply }(\mathrm{s})=\text { demand (d) at baseline] } \\
\text { High: integrated model that considered demand, need and supply ( } \mathrm{s}<>\text { dat } \\
\text { baseline) }\end{array}$ & $\begin{array}{l}\mathrm{N}=4 \\
\mathrm{~N}=6 \\
\mathrm{~N}=4\end{array}$ \\
\hline $\begin{array}{l}\text { Regional } \\
\text { heterogeneity }\end{array}$ & $\begin{array}{l}\text { Low: regional heterogeneity was not considered } \\
\text { Moderate: calculations were performed on national level but anticipated } \\
\text { regional discrepancies are discussed } \\
\text { High: calculations took into account relevant regional profile of the country }\end{array}$ & $\begin{array}{l}\mathrm{N}=8 \\
\mathrm{~N}=4 \\
\mathrm{~N}=2\end{array}$ \\
\hline \multicolumn{3}{|c|}{ Need/demand factors } \\
\hline $\begin{array}{l}\text { Scope of } \\
\text { diseases } \\
\text { covered by } \\
\text { rheumatology } \\
\text { specialty }\end{array}$ & $\begin{array}{l}\text { Low: either not listed or not deemed representative (e.g. insufficient } \\
\text { number of disease groups, unjustified author's estimate etc.) } \\
\text { Moderate: stated but the probability that they are representative is limited } \\
\text { High: stated and the probability that they are representative is high }\end{array}$ & $\begin{array}{l}\mathrm{N}=3 \\
\mathrm{~N}=5 \\
\mathrm{~N}=6\end{array}$ \\
\hline $\begin{array}{l}\text { Projection of } \\
\text { population } \\
\text { development }\end{array}$ & $\begin{array}{l}\text { Low: not considered or only size of population is included } \\
\text { Moderate: age or/and sex structure and/or other factors were included } \\
\text { but using single data source and not relying on published statistics } \\
\text { High: age or/and sex structure and/or other factors were included using } \\
\text { more than one source and relying on published statistics or national } \\
\text { population projections }\end{array}$ & $\begin{array}{l}\mathrm{N}=6 \\
\mathrm{~N}=8 \\
\mathrm{~N}=0\end{array}$ \\
\hline \multicolumn{3}{|c|}{ 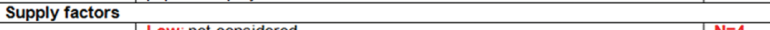 } \\
\hline $\begin{array}{l}\text { Time spent on } \\
\text { clinical } \\
\text { (rneumatologic) } \\
\text { care }\end{array}$ & $\begin{array}{l}\text { Low: not considered } \\
\text { Moderate: \% of time dedicated to clinical duties was defined without } \\
\text { detailed estimation of number, duration, and type of visit } O R \text { \% of time } \\
\text { dedicated to clinical duties was calculated through estimating the number, } \\
\text { duration and type of visits, but using single data source } \\
\text { High: } \% \text { of time dedicated to clinical duties was calculated through } \\
\text { estimating the number, duration and type of visits, using more than one } \\
\text { published data source }\end{array}$ & $\begin{array}{l}\mathrm{N}=4 \\
\mathrm{~N}=10\end{array}$ \\
\hline $\begin{array}{l}\text { Demographic } \\
\text { trends in } \\
\text { workforce }\end{array}$ & $\begin{array}{l}\text { Low: not considered } \\
\text { Moderate: one demographic trend (e.g. ageing, feminization, millennial } \\
\text { trend) was considered } \\
\text { High: more than one demographic trends were considered }\end{array}$ & $\begin{array}{l}\mathrm{N}=6 \\
\mathrm{~N}=3 \\
\mathrm{~N}=5\end{array}$ \\
\hline
\end{tabular}

Conclusions: The existing evidence on workforce prediction in rheumatology and other fields is scarce, heterogeneous and of low or moderate quality. The workforce prediction quality appraisal tool will enable future evaluation of workforce prediction studies. This review informs the EULAR points to consider for the conduction of workforce requirement studies in rheumatology.

\section{REFERENCE:}

1. Dejaco C, et al. Arthritis Care Res (Hoboken) 2016.

Disclosure of Interest: None declared DOI: 10.1136/annrheumdis-2018-eular.2228

\section{FRI0632 IMPACT OF A TIGHT CONTROL MULTIDISCIPLINARY RHEUMATOLOGY PROGRAM ON THE QUALITY OF LIFE OF PATIENTS WITH AUTOINMUNE DISEASES IN COLOMBIA}

R. Pineda-Tamayo ${ }^{1}$, M.-A. Alzate ${ }^{1}$, D. Hernandez-Parra ${ }^{1}$, D. Echeverry ${ }^{1}$, P. OrtizSalazar', A. Rojas-Villarraga'. ${ }^{1}$ Clinical information group, Artmedica IPS, Medellín Colombia

Background: Autoimmune diseases are chronic inflammatory pathologies of complex etiology and variable clinical expression that usually affect young individuals, generating chronical pain and altering their functionality. Therefore, one of the mainstays of the treatment is to improve the quality of life (QoL) of these patients

Objectives: To determine the impact of a tight control multidisciplinary rheumatologyprogram in the QoL of patients with rheumatoid arthritis (RA), Systemic lupus erythematosus (SLE) and seronegative spondyloarthropathies (SpA).

Methods: A analytical quasi-experimental study was conducted were 3812 patients with RA, 590 patients with SLE and 605 patients with SpA were included and followed between February 2015 and December 2016. Two separated measurements of QoL were developed through the EuroQol Five Dimensions Questionnaire (EQ-5D) by time trade-off (TTO) valuation technique and the visual analogue scale valuation technique (EQ-VAS). Sociodemographic characteristics 